\title{
A New Route to Synthesize MnSe Thin Films by Chemical Bath Deposition Method
}

\author{
İshak Afsin Karipera, ${ }^{a, *}$ \\ ${ }^{a}$ Erciyes University, Education Faculty, 38039, Kayseri, Turkey \\ ${ }^{b}$ Erciyes Teknopark, 1 nolu bina, No: 41, 38039, Kayseri, Turkey
}

Received: February 22, 2017; Revised: November 09, 2017; Accepted: December 04, 2017

\begin{abstract}
Manganese selenide (MnSe) crystalline thin film was produced with chemical bath deposition on substrates (commercial glass). Transmittance, absorption, optical band gap and refractive index were investigated by UV/VIS spectrum. The hexagonal form was observed in the structural properties in XRD. The structural and optical properties of the MnSe thin films were analyzed at different pHs. SEM and EDX analysis were used for the surface analysis in the films. The films had the best crystalline at $\mathrm{pH}$ : 9. At $\mathrm{pHs}$ of 11 and 10 the $\mathrm{MnSeO}_{4}$ structure was observed. The films with the lowest film thickness were found in baths prepared with $\mathrm{pH}: 11$. The highest refractive index was observed in films produced with a $\mathrm{pH}$ of 10 at a film density of 1.96. The grain size of MnSe thin films has a higher value at pH: 9 .
\end{abstract}

Keywords: MnSe thin films, Chemical Bath Deposition, Bath $\mathrm{pH}$.

\section{Introduction}

Manganese selenide (MnSe) and its thin film are good semiconductors. MnSe thin films have attracted interest due to their semiconductivity and magnetism properties. MnSe thin films are crystallized in a cubic structure with a lattice constant $(\mathrm{a}=\mathrm{b}=\mathrm{c}=5.462 \AA)$ and in a hexagonal structure with lattice constants $(\mathrm{a}=3.63 \AA ; \mathrm{c}=5.91 \AA)$. The band gap of MnSe has a value ranging from 1.13 to $1.25 \mathrm{eV}^{1-4}$. Little is known about MnSe thin film, because only a few researchers have investigated these thin films.

Heimbrodt et al. produced MnSe thin films with molecular beam epitaxy method and they investigated optical properties of MnSe thin films ${ }^{4}$. The optical band gap of the films estimated as $1.22 \mathrm{eV}$. Tomasini et al. produced MnSe thin films with organometallic vapor phase epitaxy method and they investigated structural properties of MnSe thin films ${ }^{5}$. They observed that the average grain size and the dislocation density of the films were inversely correlation with deposition temperature. Murali and Trivedi have obtained MnSe thin films by a different method: brush plating method. They studied films' properties using X-ray diffraction, scanning electron microscopy, energy dispersive analysis by X-rays, optical absorption and Raman spectroscopic measurements, respectively ${ }^{6}$. They obtained cubic $\mathrm{MnSe}$ thin films and observed (220), (311), (422) orientations of the MnSe crystalline peaks. Mahalingam et al. obtained MnSe thin films by electrodeposition method ${ }^{7}$. Mahalingam and his friends researched optical and electrical properties of the films.

All of the different methods used to produce MnSe thin films and which properties were investigated at these studies according to literature. It can be find a lot of studies for producing $\mathrm{MnSe}$ thin films in the literature. In this investigation $\mathrm{MnSe}$ thin film was produced with a new

*e-mail: akariper@gmail.com chemical bath deposition method, and its structural and optical properties were investigated. We observed that the optical properties of MnSe could be controlled with the $\mathrm{pH}$ of the chemical bath. The production of MnSe thin film with this new method namely with chemical bath deposition is very difficult and nobody as yet has produced it.

\section{Experimental}

The selenium source solution is very important in this study and must be prepared in the following way. Twenty milliliters concentrate 1-4 dioxane and 0.01 mol solid selenium are added to a beaker with $0.01 \mathrm{~mol} \mathrm{KOH}$. The mixture is heated at $80^{\circ} \mathrm{C}$ until the 1-4 dioxane evaporates completely. $\mathrm{KOH}+\mathrm{Se}$ gel remains at the bottom of the beaker. Then $0.01 \mathrm{~mol} \mathrm{LiAlH}_{4}$ is added immediately to the beaker before the gel cools. Distilled water is added then slowly to the beaker. The solution is mixed at $1000 \mathrm{rpm}$ and is completed with distilled water to $100 \mathrm{~mL}$. Caution is required when $\mathrm{LiAlH}_{4}$ added as the reaction can be flammable. The mixture is filtered before being added to the chemical bath. The $\mathrm{pH}$ of the solution was 11 .

The components of the baths were $8 \% \mathrm{HCl}, 5 \mathrm{~mL}$ $0.001 \mathrm{M}$ manganese nitrate, $5 \mathrm{~mL}$ of the prepared Se source solution, and $5 \mathrm{~mL}$ triethanolamine (TEA). Firstly, $5 \mathrm{ml}$ $0.001 \mathrm{M}$ manganese nitrate, $5 \mathrm{ml}$ Se source solution and 5 mL TEA were added to a beaker which was filled with 40 $\mathrm{ml}$ deionized water. To adjust the $\mathrm{pH}$ of the bath $8 \% \mathrm{HCl}$ was used. In order to adjust the $\mathrm{pH}$ value of the solution to $10,9,8 ; 2,4$ and $8 \mathrm{~mL}$ of $8 \% \mathrm{HCl}$, respectively, were added to the solutions. The main solution $\mathrm{pH}$ was 11 . The $\mathrm{pH}$ values of the chemical baths were determined using a $\mathrm{pH}$ meter (Lenko mark $6230 \mathrm{~N}$ ). The bath remained for 3 hours at $50{ }^{\circ} \mathrm{C}$. 
The crystalline structure of the MnSe was confirmed by X-ray diffraction (XRD) with a $\mathrm{CuK} \alpha_{1}$ radiation source (Rikagu $\operatorname{RadB}$ model, $\lambda=1.5406 \AA$ ) over the range $10^{\circ}$ $<2 \theta<90^{\circ}$ at a speed of $3^{\circ} \mathrm{min}^{-1}$ with a step size of $0.02^{\circ}$. The surface properties of all films were investigated using an EVO 40-LEO computer controlled digital scanning electron microscope (SEM). Chemical analysis by EDX was performed with an EDX spectrometer attached to the SEM. The optical measurements were determined by a Hach Lange 500 spectrophotometer at room temperature by placing an uncoated identical commercial glass substrate in the reference beam. The optical spectrum of the thin films was recorded in the wavelength range of 300-1100 nm.

\section{Results and Discussion}

The chemical reactions for the deposition of manganese selenide film taking place in the bath are described below. Manganese ions $\left(\mathrm{Mn}^{+2}\right)$ combined with selenide $\left(\mathrm{Se}^{-2}\right)$ to form an insoluble MnSe in the bath ${ }^{8}$.

$$
\begin{gathered}
\mathrm{Se}_{(\mathrm{s})} \stackrel{\mathrm{KOH} / \mathrm{LiAlH} 4}{\longrightarrow} \mathrm{Se}_{(\mathrm{aq})}^{-2} \\
\mathrm{Mn}_{(\mathrm{aq})}^{+2}+\mathrm{Se}_{(\mathrm{aq})}^{-2} \longrightarrow \mathrm{MnSe}_{(\mathrm{s})}
\end{gathered}
$$

Equations (1) and (2) show the formation of $\mathrm{Se}^{2-}$ and MnSe. Equation (1) can be converted to $\mathrm{SeO}_{4}{ }^{2-}$ and $\mathrm{SeO}_{3}{ }^{2-}$, so the Se source must be used in the bath immediately.

The XRD patterns of the MnSe films deposited by $\mathrm{CBD}$ at different $\mathrm{pH}$ values are shown in Figure 1 (a: $\mathrm{pH}$ 11, b: $\mathrm{pH} 10$, c: $\mathrm{pH} 9, \mathrm{~d}: \mathrm{pH}$ 8) and the XRD data of the films are compared with the ASTM values in Table 1 . The peaks of the films were hidden in amorphous structures at $\mathrm{pH}$ : 11,10 and 8 , but the peak of $\mathrm{pH} 9$ is sharper than the

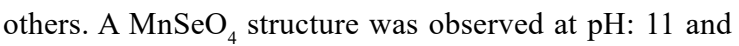
10. This is not surprise, because selenium anion leans to selenite (or selenate). The excess $\mathrm{OH}^{-}$anions convert to selenate in aqua solutions. The structure remained selenide at $\mathrm{pH}$ : 9 and 8 because of the effect of hydroxyl anions being less than at $\mathrm{pH}: 11$ and 10. This is an important point namely that the $\mathrm{pH}: 9$ and 8 can be used as a special method for producing $\mathrm{MnSe}$ thin films. The face-centered cubic structure was observed at $\mathrm{pH}: 8$ and $9(\mathrm{a}=\mathrm{b}=\mathrm{c}=5.462$ $\AA$ ). The mixture phase observed at $\mathrm{pH}$ : 10 were like the transition phase of $\mathrm{MnSeO}_{4}$ to $\mathrm{MnSe}$. P. Tomasini et al. observed the XRD peaks of MnSe thin films at $13-14^{\circ}$ ( $\beta$-MnSe with 111 Miller index), and at $16-17^{\circ}(\alpha-\mathrm{MnSe}$ with 200 Miller index $)^{5}$. In their study they achieved the annealing of the films at $200-400{ }^{\circ} \mathrm{C}$, so their values are very different from this study and the films were grown on Si substrates. The XRD values of this study show a little deviation, the highest deviation is $0.57^{\circ}$ at $\mathrm{pH}$ : 11 and 9 . These results are compatible with standard values.
The structural parameters, such as grain size (D), and dislocation density $(\delta)$, for all films were evaluated by the XRD patterns and are presented in Fig. 2. The grain size of the thin films was calculated by XRD patterns using Debye Scherrer's formula ${ }^{9}$,

$$
D=\frac{0.9 \lambda}{B \cos \theta}
$$

where $\mathrm{D}$ is the grain size, $\lambda$ is the $\mathrm{X}$-ray wavelength used, $\beta$ is the angular line width at half-maximum intensity in radians and $\theta$ is the Bragg angle. The grain size and dislocation density of the films are calculated using the FWHM of (111) pH: 11, (111) pH: 10, (111) pH: 9 and (200) pH: 8 peaks obtained using Scherrer's method and are the highest intensity peaks of the XRD patterns. The dislocation density $(\delta)$ which give more information on the amount of defects in the films, is given by the formula ${ }^{8}$,

$$
\delta=\frac{1}{D^{2}}
$$

Higher $\delta$ values indicate lower crystallinity levels for the films and indicate the amount of defects in the structure. Films with smaller $\delta$ values indicate better crystallization of the films ${ }^{8}$.

$$
N=\frac{t}{D^{3}}
$$

where $\mathrm{N}$ is the number of crystallites per unit area. The higher $\mathrm{N}$ value indicates an abundance of crystallization.

The grain size of MnSe thin films have a higher value at $\mathrm{pH}$ : 9. The grain size of the films changed to at 4.63 , $4.37,5.78$, and $5.28 \mathrm{~nm}$ depending on the film thickness. In particularly, crystallinity at $\mathrm{pH}: 9$ and 8 affected the grain size. The dislocation density and the number of crystallites per unit area values were drawn as parallel curves, as expected, but inversely correlated with the grain size. The dislocation density at pH: 9 had a lower value than the others. These results were in agreement with the XRD data, because a higher intensity value was seen at $\mathrm{pH}$ : 9 . The number of crystallites per unit area value was the lowest value, in order to the grain size of $\mathrm{pH}$ : 9 was the highest value with 5.78 $\mathrm{nm}$. Akaltun et al. produced CdSe thin film with 225-400 $\mathrm{nm}$ film thickness and they found that the grain size was decreased with the dislocation density (the grain size: 6.89 , 14.49, $18.58 \mathrm{~nm}$ and dislocation density: 210.65, 47.62, $28.96 \times 10^{-4} \mathrm{~nm}^{-2}$, respectively), as in this study ${ }^{9}$.

The film thicknesses of the films vs. plot at different pHs is drawn in Figure 3. The film thicknesses of the films were determined with AFM device. We used tapping mode with AFM and used averaged values. The film thicknesses of the films changed with bath pH's to $79,84,126,117 \mathrm{~nm}$ and $\mathrm{pH}: 11,10,9$ and 8 . Researchers found that the film thickness was not correlated with the deposition $\mathrm{pH}$ or deposition time and the other parameters. ${ }^{9,10-15}$. The film 


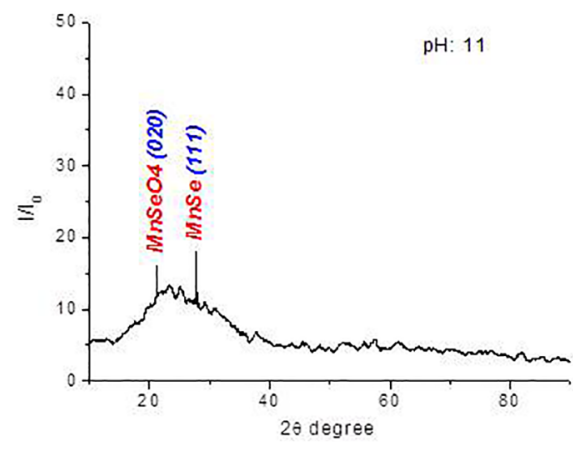

Fig. 1. (a)

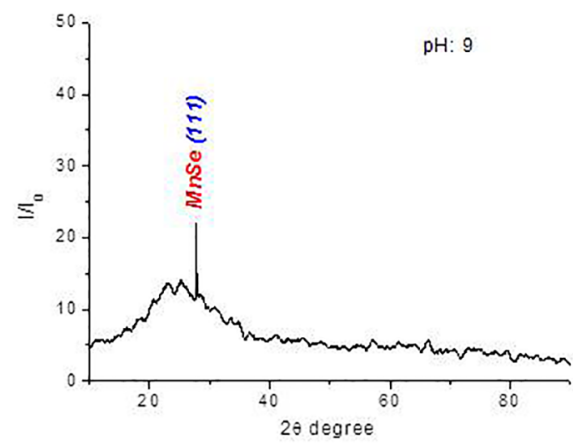

Fig. 1. (c)

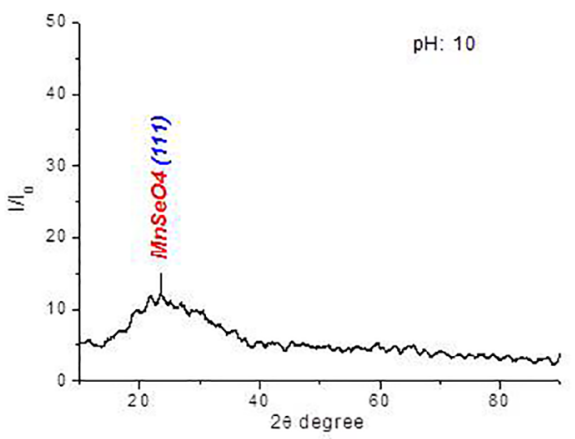

Fig. 1. (b)

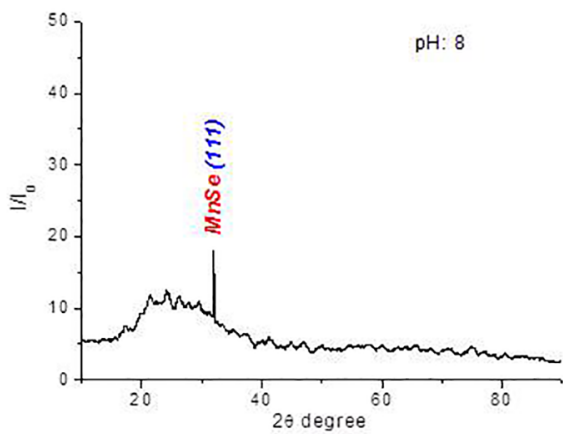

Fig. 1. (d)

Figure 1. X-ray patterns of MnSe films deposited in a bath solution at: (a) $\mathrm{pH}: 11$, (b) $\mathrm{pH}: 10$, (c) $\mathrm{pH}: 9$ and (d) $\mathrm{pH}: 8$.

Table 1. XRD data of ASTM values versus films

\begin{tabular}{ccccc}
\hline $\mathrm{pH}$ & $\begin{array}{c}\text { ASTM } \\
\text { Data File }\end{array}$ & $\begin{array}{c}\text { ASTM } \\
\text { Value }\end{array}$ & $\begin{array}{c}\text { Observed } \\
\text { Value }\end{array}$ & Miller İndex \\
\hline \multirow{2}{*}{11} & $017-0840$ & 21.76 & 21.27 & $\mathrm{MnSeO}_{4}(020)$ \\
& $011-0683$ & 28.29 & 27.72 & $\operatorname{MnSe}^{2}(11)$ \\
10 & $017-0840$ & 23.51 & 23.71 & $\operatorname{MnSeO}_{4}(111)$ \\
9 & $011-0683$ & 28.29 & 27.72 & $\operatorname{MnSe}^{2}(111)$ \\
8 & $011-0683$ & 32.75 & 32.33 & $\operatorname{MnSe}(200)$ \\
\hline
\end{tabular}

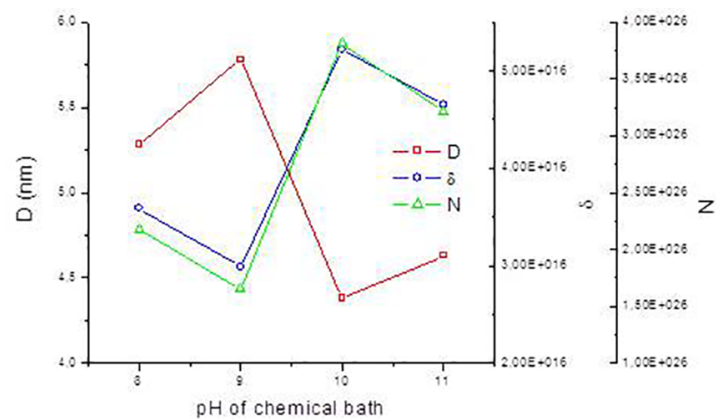

Figure 2. The grain size (D), dislocation density $(\delta)$, and number of crystallites per unit area $(\mathrm{N})$ values of MnSe thin films at different $\mathrm{pHs}$. thickness decreased at pH: 8 in this study, suddenly. The film thickness increased to 117 and $126 \mathrm{~nm}$ until $\mathrm{pH}: 10$. After $\mathrm{pH}: 10$, the film thickness decreased to 84 and $79 \mathrm{~nm}$. The films preferred to grow on crystalline structure at $\mathrm{pH}: 8$ and 9 , because the grains of these films were head to axis with regularly. The vander Walls forces of the surface of the films in the crystalline structure were affected much more than in the amorphous structure, so the grains accumulateLd at the surface of the crystalline structure.

The transmittance $(\mathrm{T})$ for the MnSe thin film can be calculated using reflectivity $(\mathrm{R})$ and absorbance (A) spectra from the following formula ${ }^{8-9}$ :

$$
T=(1-R)^{2} e^{-A}
$$

Fig. 4 shows the transmittance and reflectance of $\mathrm{MnSe}$ thin films obtained from baths with different $\mathrm{pHs}$ and Fig. 5 shows the absorbance of MnSe thin films obtained from baths with different $\mathrm{pHs}$. The transmittance curve had the lowest value at $\mathrm{pH}$ : 9 and the reflectance curve had the highest value at $\mathrm{pH}$ : 9. The absorbance curve had a higher value than the others at $\mathrm{pH}$ : 9. The reason is that the light interacts with 


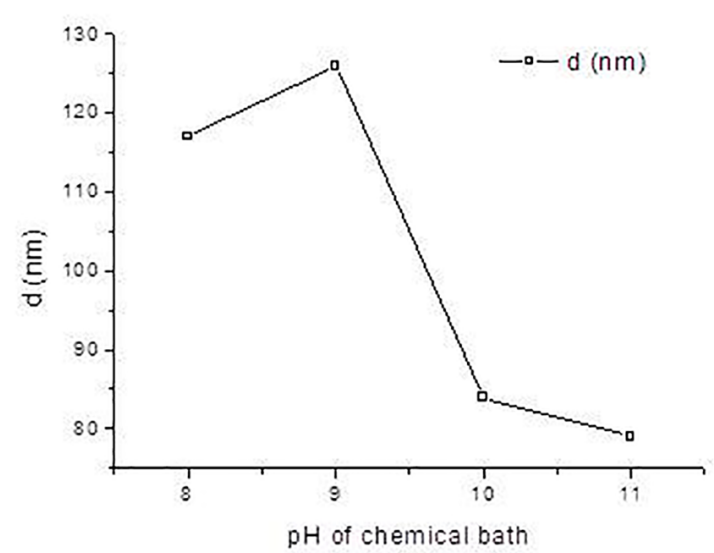

Figure 3. Plot of the film thickness (d) vs. different pHs.
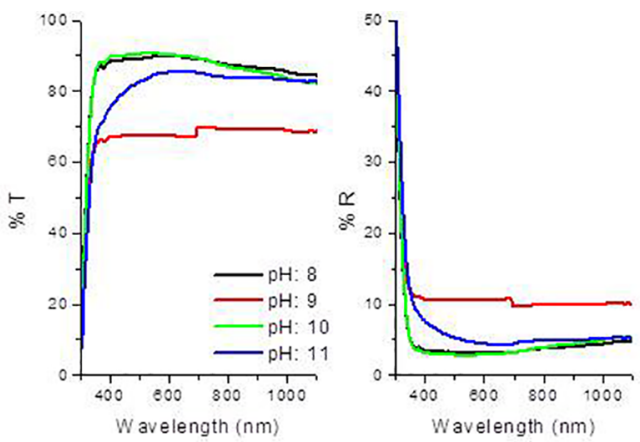

Figure 4. Transmittance and reflectance of MnSe thin films obtained from baths with different $\mathrm{pHs}$.

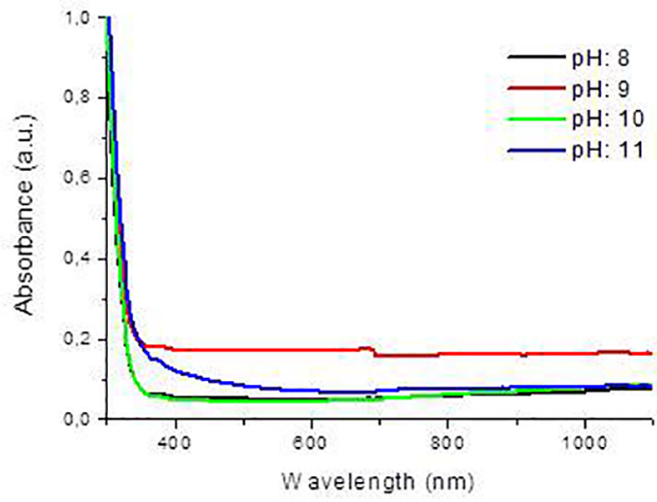

Figure 5. Absorbance of MnSe thin films obtained from baths with different $\mathrm{pHs}$.

bigger grain size better than with the others. The bigger grain size absorbs much more light than smaller grain size. The reflectance behaved like the absorption curve. Demidenko et al. produced MnSe thin films with $0.6 \mu \mathrm{m}$ film thickness ${ }^{15}$. They found the transmission of the film to be about $14 \%$ at $550 \mathrm{~nm}$. We observed the transmission at 89.53, 67.29, 90.57 and 84.52 with $117,126,84$ and $79 \mathrm{~nm}$ film thickness. Also the reflectance values were $3.07,10.59,2.76$ and $4.64 \mathrm{~nm}$ at $550 \mathrm{~nm}$. The film thickness is the cause of the different results. No researcher has measured the transmittance and reflectance of MnSe thin films at 300-1100 nm.

The refractive index and extinction coefficient for films are given by the following formulas ${ }^{8}$ :

$$
\begin{gathered}
n=\frac{(1+R)}{(1-R)}+\sqrt{\frac{4 R}{(1-R)^{2}}-k^{2}} \\
k=\frac{\alpha \lambda}{4 \pi}
\end{gathered}
$$

The refractive index is shown in Fig. 6. The refractive index and extinction coefficient of MnSe thin films were shown to be parallel with film thickness and the grain size at 1.42, 1.96, 1.39, 1.54 (refractive index) - 0.003, 0.012, 0.003, 0.005 (extinction coefficient) and were 117, 126, 84 and 79 $\mathrm{nm}$ (film thickness) and 4.63, 4.37, 5.78, 5.28 nm (grain size), respectively. Eid et al. also measured the refractive index of $\mathrm{Cd}_{(1-\mathrm{x})} \mathrm{Mn}_{\mathrm{x}}$ Se thin film at 600-2400 nm when $\mathrm{x}=0.90^{16-17}$. They calculated the refractive index to be about 2.618 with 697 $\mathrm{nm}$ film thickness. The cadmium and film thickness affected the refractive index. Also, the film thickness in this study is thinner than that reported in the literature.

The dielectric constant $(\varepsilon)$ can be calculated by the following relation:

$$
\varepsilon \varepsilon=\frac{4 R}{1-R^{2}}-k^{2}
$$

The dielectric constant changed with the refractive index at $0.131,0.530,0.116,0.204$ and at $1.42,1.96,1.39$ and 1.54, respectively, as shown in Fig. 7. The dielectric constant indicates the accessible electrical area. The higher value of dielectric constant is $\mathrm{pH}$ : 9 as expected because of the grains are oriented at a regular axis. The electrical area affects the regular structure, because the dipole moment vectors have the same orientation in the crystalline structure.

The SEM images are shown in Figure 8 at different $\mathrm{pHs}$. The SEM images indicate the structure of the films and show the surface properties. The SEM images of MnSe thin films showed that the grains were irregularly located with increased $\mathrm{pH}$. In particular, the grains were regularly located and adhered well to the substrate at $\mathrm{pH}: 9$, because the films had the best crystallinity at $\mathrm{pH}: 9$. the particles in the film sem-image get in the crystal structure are much more organized than the others. The films with amorphous structure appear to be clumping in certain regions. Because of this condensation of the grains in certain regions, X-rays interact with glass base material instead of MnSe crystals. Therefore, the XRD data of these films indicate that they are amorphous. 


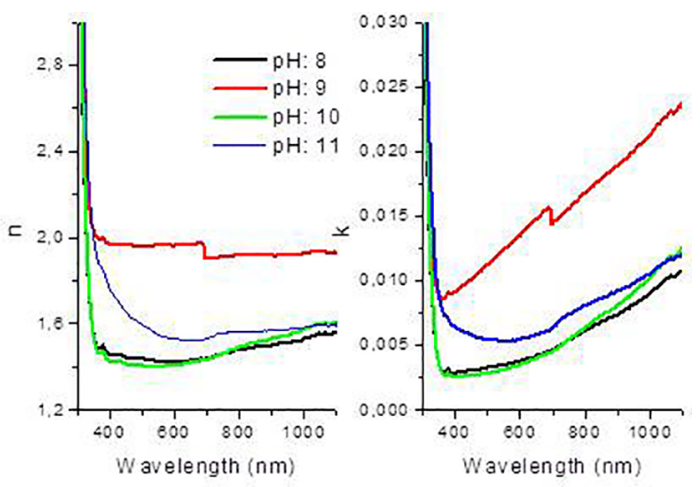

Figure 6. Plot of the refractive index and extinction coefficient of MnSe films at different $\mathrm{pHs}$.

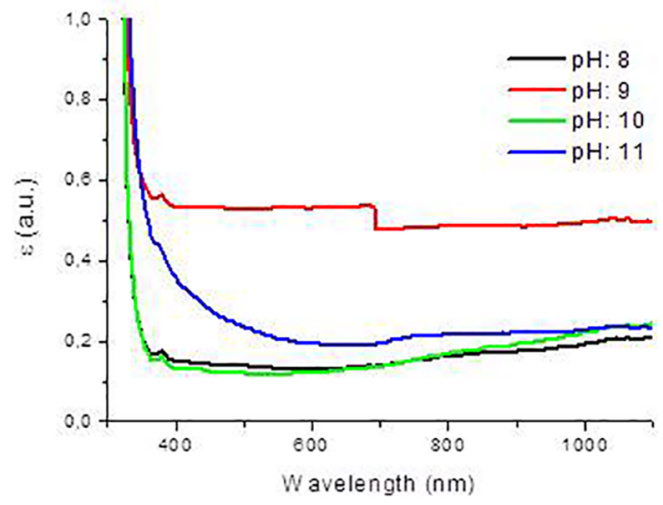

Figure 7. Plot of dielectric constant of MnSe films at different $\mathrm{pHs}$.

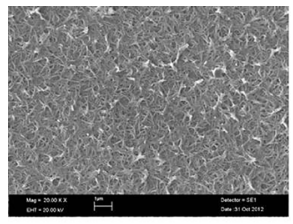

Fig. 8. (a)

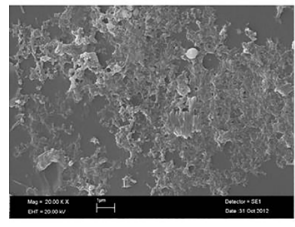

Figure 8. SEM images of MnSe films at different $\mathrm{pHs}$, (a) $\mathrm{pH}=8$, (b) $\mathrm{pH}=9$, (c) $\mathrm{pH}=10$, (d) $\mathrm{pH}=11$.

\section{Conclusion}

A new method was developed for producing $\mathrm{MnSe}$ thin films in this study. The production of MnSe thin films was scanned at different $\mathrm{pHs}$ of $11,10,9$ and 8 . The films had the best crystallinity at $\mathrm{pH}$ : 9. At $\mathrm{pHs}$ of 11 and 10 the $\mathrm{MnSeO}_{4}$ structure was observed. The grain size of the films changed to at $4.63,4.37,5.78$, and $5.28 \mathrm{~nm}$ depending on the film thickness. These results very good than the literature. The film thicknesses of the films changed with the chemical bath pH's at 79, 84, 126, $117 \mathrm{~nm}$ and $\mathrm{pH}$ : 11 , 10,9 and 8 . These results agreed with the literature. The refractive index and extinction coefficient of the MnSe thin films were shown to be parallel with film thickness and the grain size at $1.42,1.96,1.39,1.54$ (refractive index) - 0.003, 0.012, 0.003, 0.005 (extinction coefficient), which were $117,126,84$ and $79 \mathrm{~nm}$ (film thickness) and $4.63,4.37,5.78,5.28 \mathrm{~nm}$ (grain size), respectively. These results agreed with the literature and the film thickness was thinner than the literature. Especially, the raw data's (XRD) were used to in these studies.

\section{References}

1. Thanigaimani V, Angadi MA. Optical properties of MnSe thin films. Thin Solid Films. 1994;245(1-2):146-151.

2. Wu M, Xiong Y, Jiang N, Niang M, Chen Q. Hydrothermal preparation of $\alpha-\mathrm{MnSe}$ and $\mathrm{MnSe}_{2}$ nanorods. Journal of Crystal Growth. 2004;262(1-4):567-571.

3. Levy L, Feltin N, Ingert D, Pil MP. Three Dimensionally Diluted Magnetic Semiconductor Clusters Cd1-yMnyS with a Range of Sizes and Compositions: Dependence of Spectroscopic Properties on the Synthesis Mode. Journal of Physical Chemistry B. 1997;101(45):9153-9160.

4. Heimbrodt W, Goedea O, Tschentscher I, Weinhold V, Klimakow A, Pohl U, et al. Optical study of octahedrally and tetrahedrally coordinated MnSe. Wide-Band-Gap Semiconductors. 1993; 185:357-361.

5. Tomasini P, Haidouxv A, Tédenac JC, Maurin M. Methylpentacarbonylmanganese as organometallic precursor for the epitaxial growth of manganese selenide heterostructures. Journal of Crystal Growth. 1998;193(4):572-576.

6. Murali KR, Trivedi DC. Characteristics of brush plated MnSe films. In: $209^{\text {th }}$ Electrochemical Society Meetings; 2006 May 7-12; Denver, CO, USA. p. 263.

7. Mahalingama T, Thanikaikarasan S, Dhanasekaran V, Kathalingam A, Velumani S, Rhee JK. Preparation and characterization of MnSe thin films. Materials Science and Engineering: $B$. 2010;174(1-3):257-262.

8. Kariper IA, Baglayan Ö, Göde F. Fabrication and Optical Characterization of CdSe Thin Films, Grown by Chemical Bath Deposition. Acta Physica Polinica A. 2015;128:B219-B221.

9. Kariper IA. Hardness of $\mathrm{Mn}_{2} \mathrm{~V}_{2} \mathrm{O}_{7}$ thin films and its influential factors. International Journal of Minerals, Metallurgy, and Materials. 2015;22(9):987-991.

10. Akaltun Y, Yildirim MA, Ates A, Yildirim M. The relationship between refractive index-energy gap and the film thickness effect on the characteristic parameters of CdSe thin films. Optics Communications. 2012;284(9):2307-2311.

11. Yildirim MA, Ates A. Influence of films thickness and structure on the photoresponse of $\mathrm{ZnO}$ films. Optics Communications. 2010;283(7):1370-1377. 
12. Padiyan DP, Marikani A, Murali KR. Influence of thickness and substrate temperature on electrical and photoelectrical properties of vacuum deposited CdSe thin films. Materials Chemistry and Physics. 2002;78(1):51-58.

13. Ates A, Yildirim MA, Kundakci M, Astam A. Annealing and light effect on optical and electrical properties of $\mathrm{ZnS}$ thin films grown with the SILAR method. Materials Science in Semiconductor Processing. 2007;10(6):281-286.

14. Shinde VR, Lokhande CD, Mane RS, Han SH. Hydrophobic and textured $\mathrm{ZnO}$ films deposited by chemical bath deposition: annealing effect. Applied Surface Science. 2005;245(1-4):407-413.
15. Benramdane N, Murad WA, Misho RH, Ziane M, Kebbab Z. A chemical method for the preparation of thin films of $\mathrm{CdO}$ and ZnO. Materials Chemistry and Physics. 1997;48(2):119123.

16. Galyas AI, Demidenko OF, Makovetskii GI. Transmission spectra of films of $\mathrm{Mn}_{1-\mathrm{x}} \mathrm{Fe}_{\mathrm{x}}$ Se solid solutions. Journal of Applied Spectroscopy. 2007;74(1):152-155.

17. Eid AH, Seddek MB, Salem AM, Dahy TM. Preparation and Characterization of Thermally Evaporated Cd Mn Se Thin Films. Journal of Applied Sciences Research. 2008;4(3):319330 . 